East African Medical Journal Vol. 81 No. 7 July 2004

ATRAUMATIC INTRACUTANEOUS SKIN CLOSURE WITH SELF-MADE FISHING LINE SUTURE COMPARED TO COMMERCIAL THREAD

S. Freudenberg, MD., Surgical University Hospital, Mannheim of the University of Heidelberg Germany, C. Mkony, MD., Department of Surgery, Muhimbili University College of Health Sciences, University of Dar es Salaam, Tanzania, T. Wilhelm, MD., Surgical University Hospital Mannheim of the University of Heidelberg, Germany, T. Nyawawa, MD., Department of Surgery, Muhimbili University College of Health Sciences, University of Dar es Salaam, Tanzania, C. Kuhn, MD., Surgical University Hospital Mannheim of the University of Heidelberg Germany, R. Grobholz, MD, Department of Pathology of the University Hospital Mannheim, Germany, S. Post, MD., PhD., Surgical University Hospital Mannheim of the University of Heidelberg, Germany

Request for reprints to: Dr. S. Freudenberg, Chirurgische Universitatsklinik, Mannheim, Theodor-Kutzer-Ufer 1-3, 68135, Mannheim, Germany

\title{
ATRAUMATIC INTRACUTANEOUS SKIN CLOSURE WITH SELF-MADE FISHING LINE SUTURE COMPARED TO COMMERCIAL THREAD
}

\author{
S. FREUDENBERG, C. MKONY, T. WILHELM, T. NYAWAWA, \\ C. KUHN, R. GROBHOLZ and S. POST
}

\begin{abstract}
Objective: The aim of this study was to prove, whether the intracutaneous skin closure with self made fishing line suture is equivalent to commercial sutures.

Design: It was a randomised blinded animal study.

Setting: The study was performed in December 2002 at the Muhimbili University College of Health Sciences in Dar-es-salaam.

Subjects: Both German surgeons from Mannheim, and Tanzanian surgeons from Dar es salaam operated on nine one year old Tanzanian domestic sheep.

Interventions: 108 standardised cutaneous wounds on the backs of the animals were closed by intracutaneous sutures either with self produced fishing line suture or a commercial nylon suture (Ethilon $\left.{ }^{\circledR}\right)$.

Main Outcome measures: The clinical and histological outcomes, as well as the costs of this self-made fishing line suture, with a commercial nylon thread were evaluated and compared.

Results: There are no significant differences between the two sutures in histological or clinical findings, or in the reported ease of use by the surgeons. The cost of a selfproduced atraumatic thread is US\$ 0.12 , less than one-twentieth of the cost of the commercial thread.

Conclusion: Self-made fishing nylon suture has characteristics and properties in sheep skin wounds comparable to commercial nylon suture. The advantage of the commercial thread is the guaranteed quality assurance. It is discussed whether this quality assurance justifies the large price difference, and whether the self-produced thread should be recommended to surgeons in countries where the costs of surgical material often remains an obstacle for life saving operations.
\end{abstract}

\section{INTRODUCTION}

Lack of surgeons and material for surgical procedures limit access to adequate surgical treatment in poor countries. There are recent efforts to address the lack of surgeons through better training programmes in several countries(1). On the other hand, out-ofpocket payments for treatment and for the materials needed in surgical procedures are still limiting access, and are commonly requested from the patients, who have a minimal ability to pay. With increasing efforts to privatise and introduce fee-for-service procedures in poor countries, surgery is becoming less available for the poor population. In some places even vital operations are only performed after a pre-payment for surgical materials; such demands can be lethal for some patients(2). Costs for staff in poor counties are relatively low compared to the costs of surgical supplies, which are mostly imported. The reduction of the costs for material should have high priority. In developing countries the costs of surgical suture material constitutes one third of the material costs for a given operation(3).

Efforts are needed to identify, evaluate and promote affordable alternatives. The use of cheap fishing nylon thread has been proclaimed for hernia repair, abdominal wall and skin closures(9-7). Nevertheless, the use of cost-saving fishing nylon has not spread widely. The need of introducing traumatic needles with less sharpness than the single use needles may account for this.

A technique for the self-production of sharp single-use armed thread with the same qualities as commercial ones has been described recently $(8)$, This development could motivate surgeons to use this cost reducing technique. To compare these two suture materials -self made fishing nylon sutures and commercial nylon (Ethilon $\left.{ }^{\circledR}\right)$, an animal trial was initiated in Dar es Salaam, Tanzania. 


\section{MATERIALS AND METHODS}

Fishing-line suture: The self production of atraumatic suture is simple. All that is needed is an injection needle and fishing nylon thread. In our study a G $231 / 2$ injection needle (Microlence B. Braun; Tuttlingen, Germany) and fishing nylon $0.25 \mathrm{~mm}$ from the local market (Ultramid = Poly-amid 6/6) was used. The producer of the fishing nylon (BASF) confirmed the pureness of the nylon without additive or coating of the surface(9). To produce the atraumatic suture material the thread is introduced into the cavity of the needle and fixed by squeezing its end after having broken the hub (Figure $1 \mathrm{a}-\mathrm{d}$ ) (8). The thread is wrapped in a compress and autoclaved with the other surgical instruments.

Commercial suture: The cheapest commercial surgical thread for skin closure is nylon. In this study Ethilon 3-0 (Polyamid 6/6) with FS 2 needle was used. The size 3-0 corresponds to a diameter of $0.2-0.249 \mathrm{~mm}$ and is comparative to the fishing line. The costs of both sutures were recorded. The cost of the self-made suture included the salary of the local producer on a per unit basis.

The animals: After obtaining approval of the Ethical Commission in Dar es Salaam, nine one-year-old Tanzanian domestic sheep were selected and kept in a clean shadowed area of the Muhimbili University. During the study the sheep were guarded and cared for by a shepherd employed for the purpose. They were divided into three groups A,B,C with three animals each.

The skin closure: Under general anaesthesia with ketamine and barbiturates the backs of the sheep were shaved and disinfected with an iodized alcohol solution. After sterile covering 12 standardised skin cuts of $3 \mathrm{~cm}$ length and $1 \mathrm{~cm}$ depth were applied on both sides of the back of each animal. Haemostasis was performed by compression of the wounds. The wounds were then mapped and after randomisation, either the fishing line suture or the commercial thread suture was used to perform a Halsted's intracutaneous continuous skin closure. Each animal received six sutures with the commercial thread and six with the self-made fishing line suture. The sutures were performed by three different surgeons. After wound closure the wounds were covered with self adhesive wound dressings. The sheep were kept isolated, and feeding was started six hours after the surgical procedure. The sutures were removed on day 8 .

Observation of the surgeon: After each suture the time required for closure was marked, and the opinion of the surgeon if he felt comfortable with the thread was documented (very practical, practical, not practical).

Clinical observation and evaluation: Group A was observed for five days, group B for ten days and group C for 21 days before being sacrified and the excision of skin-samples. A daily wound control was performed by an independent surgeon, who judged the inflammatory reaction by noting and scoring the presence of inflammatory symptoms using the criteria of the Hollander wound score(10) (Table 1).

Induration, elevation and breadth of the scars were judged on day 21 in order to evaluate the tendency of hypertrophic scar formation. The removal of the suture was performed by a second independent observing surgeon, who documented whether or not the procedure was easy, with problems (elevated resistance during removal) or with major problems (impossibility to remove or breakage of the thread).
Histological findings: After 5 (group A), 10 (group B) and 21 (group C) days the animals were killed, the wounds were excised, and the samples were marked and fixed in formalin. Before evaluation the sutures were removed from the specimen (group A) to allow an unbiased assessment. The histological cutting was made transversely through the middle third of the wound. Haematoxylin eosin staining and histological examinations were performed at the Department of Pathology, University Hospital Mannheim Germany. At the depth of $3 \mathrm{~mm}$ from the skin surface and in a field of $1 \mathrm{x} 10 \mathrm{~mm}^{2}$ around the wound, the following objectives were judged: (i) the size (in $\mathrm{mm}$ ) and form (round or irregular) of the stitch canal, (ii) bleeding as a sign of traumatised tissue was assessed by planometric counting the fields of extravasal red blood cells in percentage of the defined surface (lx 10 $\mathrm{mm}^{2}$ ), (iii) the number of 9 . The number of material, (iv) the number of giant cells to estimate the foreign body reaction to the suture material, (v) the percentage of fibrin fibers in percentage.

Statistical method: As the logistic regression analysis is a model that is tailored to fit a binary dependent variable, it was used to analyse and compare the registered data using the Wald Chi square and the Fisher Exact Test (SAS software).

\section{RESULTS}

Observation of the surgeons: The time needed from the first stitch to the last exit of the needle ranged from $120 \mathrm{sec}$ to $360 \mathrm{sec}$. There was a statistically significant difference between the average time required for the procedure by the three surgeons: Surgeon I: $3.5 \mathrm{~min}$, Surgeon II: $4.4 \mathrm{~min}$, Surgeon III: $2.8 \mathrm{~min}(\mathrm{p}<0.001)$. The time needed for the suture with the self-made fishing line suture did not differ significantly from the time needed for the suture with the commercial thread. 3.63 minutes (Ethilon®) vs. $3.55 \mathrm{~min}$ (Fishing line) $\mathrm{p}=0.3599$.

All three surgeons judged both suture materials to be "very practical". During two of 54 sutures with the self-made suture the nylon thread slipped out from the needle because the squeezing of the end of the needle was not tight enough to fix the thread in the cavity of the injection needle; the suture had to be removed to start from new. One surgeon (III) preferred to bend the straight needle of the self-made suture before starting. But later on in the study he left the needle straight and considered the straight needle as very practical too once he got used to it.

Concerning the removal of the threads there were minor difficulties (higher resistance during pulling) to remove the thread in five cases (two in the self made ones and three with the commercial thread) and two major problems with rupture of the thread (one in the self made ones and one with the commercial thread). These problems were due to technical mistakes during suturing either by irregular suturing with large back stitches or by making accidentally a nod during suturing. There was no significant difference between the two materials regarding the removal of the sutures $(p=1)$. 
Figure 2

Figure la

The suture is threaded through the sharp opening of the injection needle

Figure lb

The hub is broken by repeated bending of the needle and removed by pulling over the suture

\section{Figure lc}

The proximal end of the needle is pinched with the lock of a needle holder to fix the suture to the needle
Time needed for the suture with the different suture materials by the three different surgeons $A, B, C$

\section{Table 3}

Total clinical inflammation score points of fishing line vs. ethilon ${ }^{\circ}$ over the time (5 days)

\section{Figure 4}

Number of granulocytes in a field of $1 \times 10 \mathrm{~mm} 2$ around the wound edges in a depth of $3 \mathrm{~mm}$ after 5,10 and 21 days for ethilon ${ }^{\circledR}$ and fishing line

Table 1

\section{Figure Id}

The proximal end of the needle is pinched with the lock of $d$ needle holder to fix the suture to the needle
Clinical inflammatory score (Hollander Score)

\begin{tabular}{ll}
\hline Score for inflammation & Points \\
\hline elevated temperature of the skin & 1 \\
Swelling around the wound & 1 (for each \\
& $5 \mathrm{~mm}$ the wound) \\
Spontaneous discharge & 2 \\
Presence of discharge after pressing & 1 \\
Dehiscence of the wound & 2
\end{tabular}

\section{CLINICAL FINDINGS}

Inflammatory signs: The total score points showing clinically inflammatory reaction varied under the different animals from 0 to 15 . After six days no inflammatory reaction could be observed on any wound. The tendency was a continuous decrease of inflammatory reaction during the time in all animals. There were no significant differences between the clinical appearance 
of inflammatory signs under the two different suture types (Figure 3) p=0.4355.

Scar formation: In group C (21 day observation) animals with 36 wounds only one showed a slight induration of a scar sutured with Ethilon' and one showed a breadth of $2 \mathrm{~mm}$ in a scar sutured with fishing-line suture.

\section{HISTOLOGICAL FINDINGS}

Tissue trauma: Only in 21 of the 36 skin samples in group A that were taken after five days the stitch channel could be identified. In all the other 87 samples of the groups A,B,C the channel was no longer visible. The average size of the stitching channel was $0.27 \mathrm{~mm}$ $(\mathrm{SD}=0.07)$ in the fishing-line suture group, and 0.25 $\mathrm{mm}(\mathrm{SD}=0.08)$ in the commercial thread group.

In the average quantity of extravasal red blood cells in the area of $10 \mathrm{~mm} 2$ around the wound $0.7 \%$ of the surface was in group A with high individual variations $(0.1 \%$ to $4 \%)$. In the groups $\mathrm{B}$ and $\mathrm{C}$ extravasal blood was negligible in the focused area. There was no significant. difference in the amount of observed extravasal blood between the two different sutures $(\mathrm{p}=0.5697)$.

Inflammatory reaction: The average number of granulocytes in a field of $1 \mathrm{x} 10 \mathrm{~mm}$ around the wound diminished from 286 in group A, to 160 in group B, and to 134 in group $\mathrm{C}$. There was no significant difference at any time of evaluation in the observed number of granulocytes in the area of the stitch channel between Ethilon" and fishing line $\mathrm{p}(\mathrm{A})=0.2996$, $\mathrm{p}(\mathrm{B})=0.4726$, and $\mathrm{p}(\mathrm{C})=0.5668$.

Foreign Body reaction: Giant cells were observed at any time of evaluation. In group $\mathrm{A}$ an average of 205 and in group B and C an average of less than one giant cells could be counted. There was no significant difference under the two materials $(\mathrm{pA}=0.0929$, $\mathrm{pB}=0.1234, \mathrm{pC}=0.7395$ ).

The presence of fibrin fibres spreading into the wound was increasingly observed in all groups over time. There was no significant difference in the amount of topometricaly evaluated fibrin fibres between the two materials. (Group A p=l, Group B p=0.6603, Group $\mathrm{pC}=0.1212$ ). There was no granulation tissue growing over the wound edges in any of the wounds.

Costs of sutures: A 3-0 Ethilon suture with sharp needle costs US\$2.30 if it is imported to Dar es Salaam. The total per unit cost of the self-made fishing-line suture is US\$ 0.12 , which is approximately $5 \%$. of the price of the commercial thread. This is based on the following calculations: $100 \mathrm{~m}$ of $0.25 \mathrm{~mm}$ fishing nylon costs US\$1.10, or US\$0.06 for $50 \mathrm{~cm}$. The price for a 23.5 G injection needle in Dar es Salaam is US\$0.04. The price of the wrapping compress is not calculated, as it is used later for the wound dressing. The time needed to produce and to wrap 100 atraumatic fishing line sutures is 80 minutes, or 48 seconds per suture. The salary of a nurse for 50 seconds in Dar es Salaam (with all costs) is less than US\$0.02.

\section{DISCUSSION}

All surgeons judged both sutures as "very practical". There was no additional time required for either of the sutures. Concerning the clinical and histological appearance of an inflammatory and foreign body reaction, trauma of the tissue or appearance of kelloid evolution, there was no significant difference between the two suture materials, hence, no difference in clinical effects could be identified in the trial comparing the self-made fishing line suture and commercial suture. Although there have been previous studies involving fishing nylon(4-7), to our knowledge there has been no randomised studies comparing it with commercial nylon suture.

The only identifiable differences between the two sutures are their cost and the quality assurance offered by the commercial brand. Regarding the price difference, the money spent for one commercial thread would allow 20 surgical skin closures to be performed with the selfmade fishing line suture. The implied savings to a surgical unit under circumstances where the price for the material of a caesarean section is around US\$20,- is that every tenth operation could be performed for free!

Quality assurance (QA) is important, as it offers valid and sustainable confirmation of manufacturing quality for a given product. International QA standards for health devices are high, but unlikely to justify or account for the 20 -fold difference in price between the two suture products. The outcome of the trial suggests that for these self-made sutures, which were sterilised prior to use, quality was more than adequate. Local production of affordable sutures such as those described in this paper will require compliance with appropriate QA standards, but should offer an affordable product nonetheless. Local production by surgical units themselves warrants exploration.

It has been argued that use of hollow injection needles carries a higher risk of HIV or Hepatitis infection for the surgeon after an accidental needle prick compared to the use of solid needles(11). Although the risk is very low, it is not negligible. It is therefore advised that the nylon suture should be made to occupy the whole length of the channel of the needle in order to minimise collection of blood or other infectious material in the needle. It is advisable that operations on HIV or hepatitis positive patients should be performed by experienced surgeons with a minimal likelihood of needle prick accidents.

In conclusion the study has demonstrated that a cheap but good quality nylon suture assembled and sterilised in the operating room has physical and clinical properties comparable to those of commercial nylon suture. This is a significant step towards publicising widespread use of such a suture, particularly in third world countries where cost cutting is of pararnount importance if surgical care is to be made available to more of those in need. 


\section{ACKNOWLEDGEMENTS}

To the German Academic Exchange Service (DAAD) for sponsoring the academic exchange programme and to the enterprise Ethicon for the donation of the threads. We also gratefully acknowledge the support of Frank Ludwig, Camela Jost and Christel Weiss as well as the editorial input of Rachel Snow.

\section{REFERENCES}

1. Freudenberg, S., Mkony, C., Wilhelm, T. and Post, S. Medical Education. The Role of Inter-Institutional Cooperation in Surgical Training and Practice: a German-Tanzanian Model. East Afr. J. Med. 2003. (Publication in press).

2. Onwujekwe, O.E., Shu, E.N. and Okonkwo, P.O. Community financing of local ivermectin distribution in Nigeria: potential payment and cost-recovery outlook. Trop. Doct. 2000; 30:91-94.

3. Bendinelli, C., Leal, T., Moncade, F., et al. Endoscopic surgery in Senegal. Benefits, costs and limits. Surg. Endosc. 2002; 16:1488-1492.
4. Bewes, P. Abdominal closure. Trop. Doct. 2000; 30:39-41.

5. Hodges, A.M. Fishing line: a valuable suture material. Trop. Doct. 2001; 31:98-99.

6. King, M., Bewes, P., James, C. and Thornton, J. Basic methods and instruments. Primary surgery. Vol. I Oxford Medical Publications. 1990; 39-51.

7. Longombe, A.O., Ralaimiarison, A. and Lusi, K.M. The use of fishing nylon for surgery in rural areas in North East Zaire. Trop. Doct. 1993; 23:179-180.

8. Freudenberg, S., Samel, S., Sturm, J. and Trede, N. The improvised atraumatic suture: a cost reducing technique, not only for the tropics? Trop. Doct. 2001; 31:166-167.

9. Certificate BASF Quality assurance No. 8900300

10. Hollander, J.E., Singer, A.J., Valentine, S. and Henry, M.C. Wound registry: development and validation. Ann. Emerg. Med. 1995; 25:675-685. (Erratum in: Ann Emerg. Med. 1995; 26:532).

11. Pietrabissa, A., Merigliano, S., Montorsi, M., Reducing the occupational risk of infections for the surgeon: multicentric national survey on more than 15,000 surgical procedures. World J. Surg. 1997; 21:573-578. 